OPEN ACCESS

Edited by:

Tao Liu,

University of New South Wales,

Australia

Reviewed by:

Gabriele Multhoff,

Technische Universität München,

Germany

Francesco Grignani,

University of Perugia, Italy

*Correspondence:

Wei-Hua Yan

yanwhcom@yahoo.com

Specialty section:

This article was submitted to Molecular and Cellular Oncology,

a section of the journal

Frontiers in Oncology

Received: 29 May 2018

Accepted: 16 August 2018

Published: 04 September 2018

Citation:

Lin A, Zhang $X$, Zhang R-L, Zhang J-G, Zhou W-J and Yan W-H (2018) Clinical Significance of Potential Unidentified HLA-G Isoforms Without a1 Domain but Containing Intron 4 in

Colorectal Cancer Patients.

Front. Oncol. 8:361.

doi: 10.3389/fonc.2018.00361

\section{Clinical Significance of Potential Unidentified HLA-G Isoforms Without $\alpha 1$ Domain but Containing Intron 4 in Colorectal Cancer Patients}

\author{
Aifen Lin ${ }^{1}$, Xia Zhang ${ }^{1}$, Rui-Li Zhang ${ }^{2}$, Jian-Gang Zhang ${ }^{1}$, Wen-Jun Zhou ${ }^{1}$ and \\ Wei-Hua Yan ${ }^{3 *}$ \\ ${ }^{1}$ Biological Resource Center, Taizhou Hospital of Zhejiang Province, Wenzhou Medical University, Linhai, China, ${ }^{2}$ Department \\ of Gastrointestinal Surgery, Taizhou Hospital of Zhejiang Province, Wenzhou Medical University, Linhai, China, ${ }^{3}$ Medical \\ Research Center, Taizhou Hospital of Zhejiang Province, Wenzhou Medical University, Linhai, China
}

The ectopic HLA-G expression in malignancies has been extensively explored and clinical significance of the molecule was widely acknowledged. Besides previously well-documented seven isoforms (HLA-G1 -G7), other novel isoforms of HLA-G have been reported but their clinical relavenace remians evaluated. In this study, lesion HLA-G expression in 379 case-matched serial section primary colorectal cancers (CRC) were evaluated with mAb 4H84 (recognizing an epitope in HLA-G $\alpha 1$ domain), and mAb 5A6G7 (recognizing an epitope encoded by intron 4), respectively. Data showed that HLA-G positive staining with mAbs $4 \mathrm{H} 84$ and $5 A 6 G 7$ was 70.7 and $60.4 \%$, respectively. When percentage of $\mathrm{HLA}-\mathrm{G}$ expression detected with mAb $4 \mathrm{H} 84$ subtracted that with mAb 5A6G7, the difference $\left({ }_{\Delta} \mathrm{H} L A-G\right)$ with negative $\left({ }_{\Delta} \mathrm{H} L A-G_{n e g}\right)$, comparable $\left({ }_{\Delta} \mathrm{H}\llcorner A-\right.$ $\left.\mathrm{G}_{\text {com }}\right)$ and positive $\left({ }_{\Delta} \mathrm{HLA}-\mathrm{G}_{\text {pos }}\right)$ were observed in 64 (16.9\%), 159 (42.0\%), and 156 $(41.2 \%)$ cases, respectively. Noteworthy, unexpected immunostaining was observed in $44(11.6 \%)$ lesions that no staining was detected with mAb $4 \mathrm{H} 84$ but positive with mAb 5A6G7 (4H84 $\left.{ }^{\text {neg }} 5 \mathrm{~A} 6 \mathrm{G} 7^{\text {pos }}\right)$. This staining pattern was unpredictable because all seven known HLA-G isoforms containing the $\alpha 1$ domain could be recognized by the $m A b 4 \mathrm{H} 84$. Moreover, patients with ${ }_{\Delta} \mathrm{HLA}-\mathrm{G}_{\text {neg }}$ had obviously better survival than those with ${ }_{\Delta} \mathrm{H} L A-\mathrm{G}_{\text {com }}$ and ${ }_{\Delta} \mathrm{H} L A-\mathrm{G}_{\text {pos }}(0=0.017)$, and ${ }_{\Delta} \mathrm{H} L A-\mathrm{G}$ could be an independent prognostic factor for $C R C$ patients $(p=0.008)$. Our findings provides the first report that potential unidentified HLA-G isoforms is of distinct clinical significance in CRC patients.

Keywords: HLA-G, isoform, antibodies, colorectal cancer, prognosis

\section{INTRODUCTION}

The cancer promoting function of HLA-G, such as rendering comprehensive suppressive roles to various types of immune component cells and enhancing the proliferation and accumulation of immune regulatory cells have been extensively investigated (1). Different degree of aberrant ectopic expression of HLA-G in cancers has been frequently found in most of the cancers studied so far, and the conception that HLA-G expression plays critical basically and clinical parts in cancer biology or therapy was established (2). 
Besides application of the clinical tumor lesions, the direct roles of HLA-G participating in cancer progression have been demonstrated in previous studies with murine models. Data obtained from xenotumor or syngeneic immunocompetent murine tumor model revealed that both HLA-G1 or HLAG5 expression promoted tumor development by impairment of innate and adaptive immune responses but favoring the immune suppressive cells such as $\mathrm{CD} 11 \mathrm{~b}+\mathrm{Gr} 1+$ myeloidderived suppressor cells (MDSC) expansion $(3,4)$. Fortunately, these could be reversed with HLA-G and/or receptor blockade by certain antibodies. With an immunodeficient murine ovarian cancer xenotumor model, we found that HLA-G1 expressing ovarian cancer cells had stronger invasion and metastasis potential compared that with the HLA-G-negative parental cells (5). We also presented the underlying mechanisms of HLA-G in tumor progression not only related to the inhibition of NK lysis, but to the specific induction of matrix metalloproteinase-15 (MMP-15) expression (6). This finding was solidified by later studies that HLA-G5 could induce the expression and activity of MMP-2 and MMP-9 in trophoblastic cells, while knock-down the HLA-G experssion resulted in dramatically decreased expression of MMPs was also observed $(7,8)$.

It's well documented thus far, with the alternative splicing of the primary transcript of $H L A-G$, seven isoforms including four-membrane bound (HLA-G1, -G2,-G3, and -G4) and three soluble (HLA-G5, -G6, and -G7) molecules were validated. Each unique HLA-G isoform contains one to three extracellular

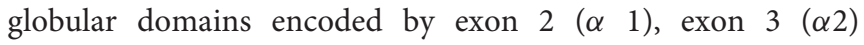
and exon $4(\alpha 3)$ respectively, and presence or absence of residues encoded by intronic sequences (IMGT/HLA database). However, these seven isoforms all contain the extracellular $\alpha 1$ domain (9, 10). Among these isoforms, HLA-G1 and soluble HLA-G5 molecule have been studied more extensively due to the commercially available antibodies. However, it's reasonable that other novel unrecognized HLA-G isoforms remains unveiled. Indeed, based on immunohistochemical and deep sequencing, an important study by Tronik-Le Roux et al. (11) recently revealed that unrecognized novel HLA$\mathrm{G}$ isoforms such as isoforms without $\alpha 1$ domain were presented in renal cancer samples. The findings raises the questions whether these novel HLA-G proteins are of clinical significance.

In our study, mAbs $4 \mathrm{H} 84$ and 5A6G7 were used to analyze the HLA-G expression by immunohistochemistry in primary colorectal cancer (CRC) samples. The percentage of HLA-G expression in tumor cells by mAbs $4 \mathrm{H} 84$ and 5A6G7 were compared, and the difference of the HLA-G expression ${ }_{\triangle}{ }_{\Delta} \mathrm{HLA}-$ G) was obtained by the percentage of HLA-G expression detected with HLA-G mAb 4H84 subtracted that with mAb 5A6G7. ${ }_{\Delta}$ HLA-G with negative $\left({ }_{\Delta} \mathrm{HLA}-\mathrm{G}_{\text {neg }}\right)$, comparable $\left({ }_{\Delta} \mathrm{HLA}-\right.$ $\left.\mathrm{G}_{\text {com }}\right)$ and positive $\left({ }_{\Delta} \mathrm{HLA}-\mathrm{G}_{\text {pos }}\right)$ were observed. Our findings revealed that patients with ${ }_{\Delta} \mathrm{HLA}-\mathrm{G}_{\text {neg }}$ had much better survival than patients with ${ }_{\Delta}$ HLA-G $-G_{\text {com }}$ and ${ }_{\Delta} H L A-G_{\text {pos }}$, and the ${ }_{\Delta}$ HLA-G could be an independent prognostic factor for CRC patients.

\section{MATERIALS AND METHODS CRC Patients}

A cohort of 379 consecutive primary CRC lesions were provided by Tissue Bank of Taizhou Hospital of Zhejiang Province (National human genetic resources platform of China YCZYPT[2017]02). Patients were diagnosed and treated at the department of Gastrointestinal Surgery in Taizhou Hospital of Zhejiang Province from November 2004 to September 2012.

The clinical stage including stage I $(n=86)$, II $(n=114)$, III $(n=169)$, and IV $(n=11)$ respectively, were classified according to the UICC and the AJCC 7th TNM staging system (12). Details of the clinical history of the patients was recorded and the last follow-up was performed at April,15th, 2014. During the period, 38 patients was lost follow-up in the cohort. Overall survival was calculated from the date of surgical operation to the event (patient death, $n=113$ ) or censored (last follow-up, $n=228$ ) with the median followup of 45.0 months. 113 cancer-related deaths was observed in 10 stage I, 26 stage II, 71 stage III and 6 stage IV CRC patients. Informed written consent was provided by all participated patients and the study protocol was approved by the institutional ethic review board, Taizhou Hospital of Zhejiang Province.

\section{Immunohistochemistry and Staining Evaluation}

Immunohistochemistry analysis for HLA-G expression was performed for each case-matched serial section primary CRC lesions on $4-\mu \mathrm{m}$ paraffin-embedded sections according to our previous study with the two anti-HLA-G murine monoclonal antibodies (mAb) 4H84 (1:500, Exbio, Prague, Czech Republic) and 5A6G7 (1:500, Exbio, Prague, Czech Republic), respectively $(13,14)$. mAb 4H84 (IgG1) was immunized with amino acids 6183 in the HLA-G alpha 1 domain, which recognizes an epitope located in the $\alpha 1$ domain in denatured heavy chain to all $\alpha$ 1 domain containing HLA-G isoforms such as HLA-G1 HLAG7. mAb 5A6G7 (IgG1) was immunized with C-terminal amino acid sequence (22-mer) of HLA-G5 and -G6 proteins coupled to ovalbumin, which recognizes HLA-G isoforms such as HLA-G5 and -G6 encoded by the retained intron 4 (IMGT/HLA database), but not cross react with the HLA-G1 isoform.

The percentage of HLA-G expression was evaluated by two reviewers who were blind to the patient clinicopathological information. The percentage of HLA-G positive tumor cells was based on the presence of HLA-G staining while irrespective the staining intensity. HLA-G positive CRC cells $>5 \%$ in a section was considered as positive (15).

Difference of the percentage of HLA-G positve tumor cells $\left({ }_{\Delta}\right.$ HLA-G) in the case-matched CRC samples was calculated by the percentage of HLA-G expression detected with mAb $4 \mathrm{H} 84$ subtracted that with $\mathrm{mAb} 5 \mathrm{~A} 6 \mathrm{G} 7$. According to the value of ${ }_{\Delta}$ HLA-G, three groups were obtained as follows: ${ }_{\Delta} \mathrm{HLA}-\mathrm{G}_{\text {neg }}$ $\left({ }_{\Delta} \mathrm{HLA}-\mathrm{G}>-5.0 \%\right),{ }_{\Delta} \mathrm{HLA}-\mathrm{G}_{\mathrm{com}} \quad\left(-5.0 \%{ }_{\Delta} \mathrm{HLA}-\mathrm{G} \leq 5.0 \%\right)$, and ${ }_{\Delta}$ HLA-G $\mathrm{G}_{\mathrm{pos}}\left({ }_{\Delta} \mathrm{HLA}-\mathrm{G}>5.0 \%\right)$. 


\section{Statistical Analysis}

Pearson chi-square test was used for categorical data analysis. Survival probability analysis were performed with Kaplan-Meier method and log-rank test. Cox proportional hazards model was used for multivariate analysis. $P<0.05$ (two-tailed) was considered as statistically significant. All statistical analysis was performed with the SPSS 13.0 software (SPSS, Inc., Chicago, IL, USA).

\section{RESULTS \\ Expression of HLA-G Probed With mAbs 4H84 and 5A6G7 in CRC}

The IHC immunostaining pattern with mAbs $4 \mathrm{H} 84$ and 5A6G7 was shown in Figure 1. In these case-matched serial section primary CRC lesions, positive HLA-G expression was observed in $70.7 \%(268 / 379)$ with $\mathrm{mAb} 4 \mathrm{H} 84$ and in $60.4 \%$ (219/379) with

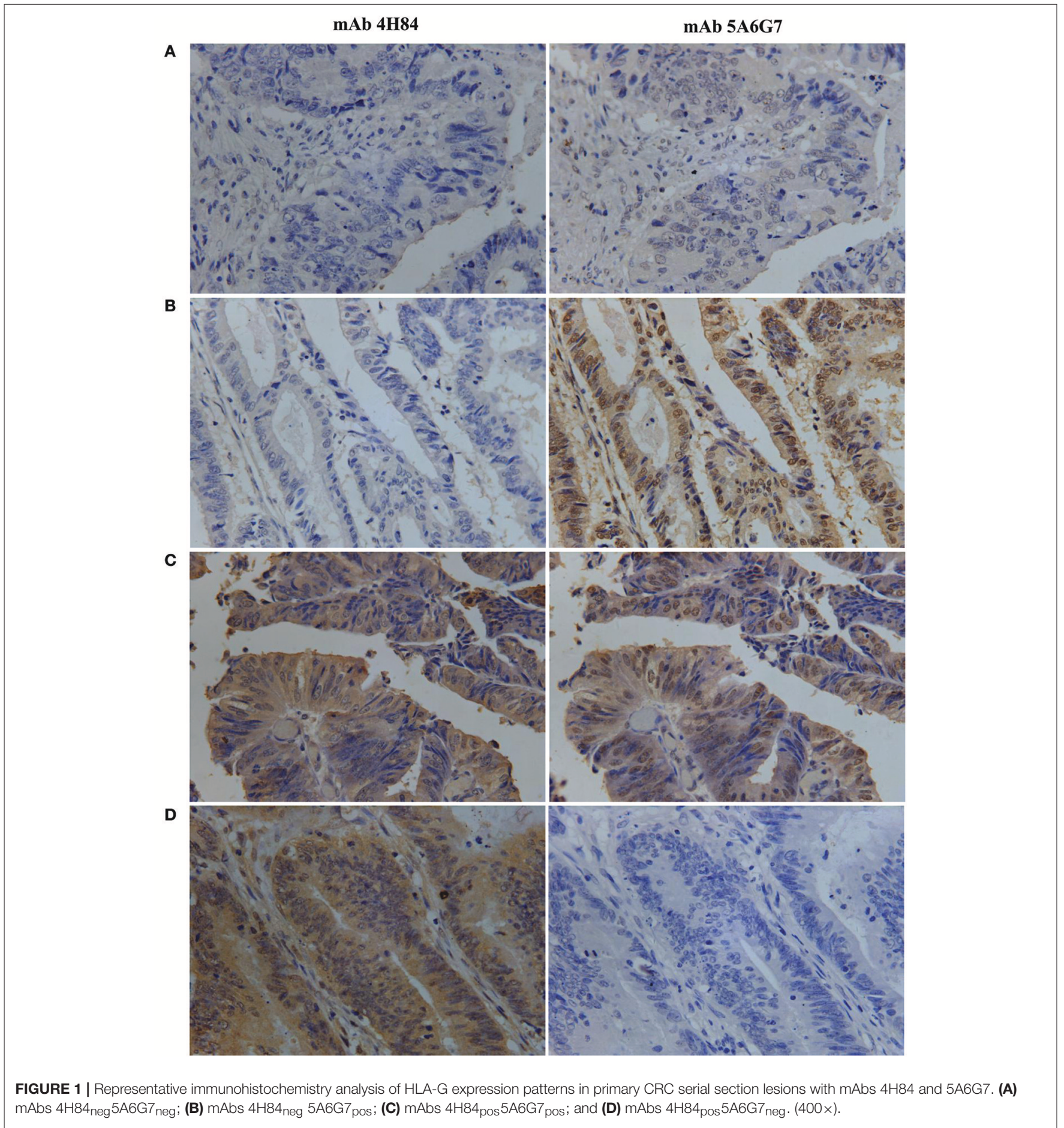


$\mathrm{mAb} 5 \mathrm{~A} 6 \mathrm{G} 7$ in CRC patients. The percentage of the HLA-G expression detected with both antibodies ranges from negative to $99 \%$. Neither the HLA-G expression status detected with $\mathrm{mAb}$ $4 \mathrm{H} 84$, nor with mAb 5A6G7 was statistical significantly related to the clinicopathological parameters such as gender, age, TNM status and AJCC clinical disease stage of CRC patients (Table 1).

Be noted, differential HLA-G expression was commonly observed in the case-matched CRC samples between the samples detected with mAbs $4 \mathrm{H} 84$ and 5A6G7. In this CRC cohort, ${ }_{\Delta}$ HLA $-\mathrm{G}_{\text {neg }}$ in $64(16.9 \%),{ }_{\Delta}$ HLA-G $\mathrm{G}_{\text {com }}$ in $159(42.0 \%)$, and ${ }_{\Delta}$ HLA $-\mathrm{G}_{\text {pos }}$ in $156(41.2 \%) \mathrm{CRC}$ cases was observed. Among the ${ }_{\Delta}$ HLA $-\mathrm{G}_{\text {neg }}$ group, unexpected immunostaining was observed in $44(11.6 \%)$ case-matched CRC lesions that no staining was detected with the mAbs $4 \mathrm{H} 84$ but with the 5A6G7 (mAbs $\left.4 \mathrm{H} 84^{\text {neg }} 5 \mathrm{~A} 6 \mathrm{G}^{\mathrm{pos}}\right)$. The data were unpredictable beacuse all seven known $\alpha 1$ domain containing HLA-G isoforms could be recognized by the mAb $4 \mathrm{H} 84$. However, both ${ }_{\Delta} \mathrm{HLA}-\mathrm{G}$ and its subgroups mAbs $4 \mathrm{H} 84^{\text {neg }} 5 \mathrm{~A} 6 \mathrm{G} 7^{\text {pos }}$ and $4 \mathrm{H} 84{ }^{\text {pos }} 5 \mathrm{~A} 6 \mathrm{G} 7{ }^{\text {neg }}$ status was unrelated to the clinicopathological parameters of CRC patients (Table 2).

The mAb 5A6G7 specifically recognize an epitope located in the C-terminal amino acid sequence of HLA-G isoforms such as HLA-G5 and -G6. However, being with the $\alpha 1$ domain, HLA-G5 and -G6 could also be recognized by the mAb 4H84. Therefore, to our prevailing knowledge, absence of mAb 4H84 labeling generally considered as the lack of HLA-G antigen expression. Noteworthy, the unexpected immunostaining pattern mAbs $4 \mathrm{H} 84^{\text {neg }} 5 \mathrm{~A} 6 \mathrm{G} 77^{\text {pos }}$ now sounds reasonable by the recent findings by the study Tronik-Le Roux et al. (11) that novel HLA-G isoforms lacks the $\alpha 1$ domain indeed exist in renal cancers.

\section{Significance of the ${ }_{\Delta} \mathrm{HLA}-\mathrm{G}$ Status to CRC Patient Survival}

Herein, Log-rank Mantel-Cox analysis of ${ }_{\Delta}$ HLA-G status and clinical parameters in CRC patient survival was evaluated. Data showed that, in addition to CRC patient tumor status, nodal status, metastasis status and AJCC clinical disease stage, both ${ }_{\Delta}$ HLA-G and its subgroups $m A$ bs $4 \mathrm{H} 84^{\text {neg }} 5 \mathrm{~A} 6 \mathrm{G} 7{ }^{\text {pos }}$ and $4 \mathrm{H} 84{ }^{\text {pos } 5 \mathrm{~A} 6 \mathrm{G} 7}{ }^{\text {neg }}$ status were significantly related to survival (Table 3).

In addition, HLA-G expression status detected by either $\mathrm{mAbs}$ $4 \mathrm{H} 84(p=0.250$, Figure 2A) or 5A6G7 $(p=0.268$, Figure 2B) were not associated with $\mathrm{CRC}$ patient survival. However, in the whole CRC cohort, ${ }_{\triangle}$ HLA-G status was dramatically relevant to the patient survival ( $p=0.017$, Figure 2C). The mean survival for ${ }_{\Delta}$ HLA-G ${ }_{\text {neg }}$ was 87.9 months $(n=57 ; 95 \% \mathrm{CI}$ : 79.4-96.4), ${ }_{\Delta}$ HLA- $\mathrm{G}_{\text {com }}$ was 71.0 months $(n=143 ; 95 \% \mathrm{CI}$ : 64.0-77.9), and ${ }_{\Delta}$ HLA-G $\mathrm{G}_{\text {pos }}$ was 67.2 months $(n=139 ; 95 \%$

TABLE 1 | HLA-G expression detected with mAbs 4H84 and 5A6G7 related to the clinical parameters in CRC patients.

\begin{tabular}{|c|c|c|c|c|c|c|c|}
\hline \multirow[t]{2}{*}{ Variables } & \multirow[t]{2}{*}{ Cases } & \multicolumn{2}{|c|}{ HLA-G (mAb 4H84) } & \multirow[b]{2}{*}{$p^{*}$} & \multicolumn{3}{|c|}{ HLA-G(mAb 5A6G7) } \\
\hline & & Neg. & Pos. (\%) & & Neg. & Pos. (\%) & $p^{*}$ \\
\hline \multicolumn{8}{|l|}{ Gender } \\
\hline Male & 214 & 69 & 145 (67.8\%) & 0.150 & 95 & 119 (55.6\%) & 0.329 \\
\hline Female & 165 & 42 & 123 (74.5\%) & & 65 & 100 (60.6\%) & \\
\hline \multicolumn{8}{|l|}{ Age } \\
\hline$\leq$ median (66 ys) & 188 & 52 & $136(72.3 \%)$ & 0.490 & 78 & 110 (58.5\%) & 0.776 \\
\hline >median & 191 & 59 & 132 (69.1\%) & & 82 & 109 (57.1\%) & \\
\hline \multicolumn{8}{|l|}{ TNM stage } \\
\hline \multicolumn{8}{|l|}{ Tumor status } \\
\hline $\mathrm{T}_{1+2}$ & 108 & 26 & 82 (75.9\%) & 0.016 & 39 & 69 (63.9\%) & 0.110 \\
\hline $\mathrm{T}_{3}$ & 256 & 79 & 177 (69.1\%) & & 117 & 139 (54.3\%) & \\
\hline $\mathrm{T}_{4}$ & 15 & 6 & 9 (60.0\%) & & 4 & $11(73.3 \%)$ & \\
\hline \multicolumn{8}{|l|}{ Nodal status } \\
\hline $\mathrm{N}_{0}$ & 201 & 57 & $144(71.6 \%)$ & 0.870 & 82 & 119 (59.2\%) & 0.421 \\
\hline $\mathrm{N}_{1}$ & 109 & 34 & 75 (68.8\%) & & 44 & $65(54.3 \%)$ & \\
\hline $\mathrm{N}_{2}$ & 69 & 20 & 49 (71.0\%) & & 34 & 35 (73.3\%) & \\
\hline \multicolumn{8}{|l|}{ Metastasis status } \\
\hline $\mathrm{M}_{0}$ & 368 & 110 & $258(70.1 \%)$ & 0.135 & 156 & 212 (57.6\%) & 0.690 \\
\hline $\mathrm{M}_{1}$ & 11 & 1 & 10 (90.9\%) & & 4 & 7 (63.6\%) & \\
\hline \multicolumn{8}{|l|}{ Disease stage } \\
\hline I & 85 & 23 & 62 (72.9\%) & 0.434 & 28 & 57 (67.1\%) & 0.207 \\
\hline$\|$ & 114 & 34 & 80 (70.2\%) & & 54 & 60 (52.6\%) & \\
\hline III & 169 & 53 & 116 (68.6\%) & & 74 & 95 (56.2\%) & \\
\hline IV & 11 & 1 & 10 (90.9\%) & & 4 & 7 (63.6\%) & \\
\hline
\end{tabular}

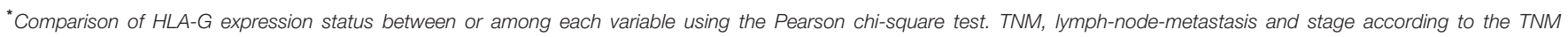
classification. 
TABLE 2 | Difference $\left({ }_{\Delta} \mathrm{HLA}-\mathrm{G}\right)$ with mAbs $4 \mathrm{H} 84$ and 5A6G7 related to the clinical parameters in CRC patients.

\begin{tabular}{|c|c|c|c|c|c|c|c|c|c|}
\hline \multirow[t]{2}{*}{ Variables } & \multirow[t]{2}{*}{ Cases } & \multicolumn{3}{|c|}{${ }_{\Delta}$ HLA-G* $^{*}$} & \multirow[b]{2}{*}{$p^{\star \star}$} & \multicolumn{4}{|c|}{ HLA-G (mAb 4H84 vs. 5A6G7) } \\
\hline & & Neg. & Com & Pos & & Cases & $4 \mathrm{H} 84^{\text {neg }} 5 \mathrm{~A} 6 \mathrm{G} 7^{\text {pos }}$ & $4 \mathrm{H} 84^{\text {pos }} 5 \mathrm{A6G} 7^{\text {neg }}$ & $p^{\star \star}$ \\
\hline Total & 379 & 64 & 159 & 156 & & 137 & 44 & 93 & \\
\hline \multicolumn{10}{|l|}{ Gender } \\
\hline Male & 214 & 35 & 96 & 83 & 0.418 & 76 & 25 & 51 & 0.828 \\
\hline Female & 165 & 29 & 63 & 73 & & 61 & 19 & 42 & \\
\hline \multicolumn{10}{|l|}{ Age } \\
\hline$\leq$ median (66 ys) & 188 & 32 & 79 & 77 & 0.996 & 68 & 21 & 47 & 0.759 \\
\hline >median & 191 & 32 & 80 & 79 & & 69 & 23 & 46 & \\
\hline \multicolumn{10}{|l|}{ TNM stage } \\
\hline \multicolumn{10}{|l|}{ Tumor status } \\
\hline $\mathrm{T}_{1+2}$ & 108 & 19 & 47 & 42 & 0.821 & 33 & 10 & 23 & 0.175 \\
\hline $\mathrm{T}_{3}$ & 256 & 41 & 107 & 108 & & 100 & 31 & 69 & \\
\hline $\mathrm{T}_{4}$ & 15 & 4 & 5 & 6 & & 4 & 3 & 1 & \\
\hline \multicolumn{10}{|l|}{ Nodal status } \\
\hline $\mathrm{N}_{0}$ & 201 & 33 & 88 & 80 & 0.634 & 65 & 20 & 45 & 0.356 \\
\hline $\mathrm{N}_{1}$ & 109 & 22 & 40 & 47 & & 46 & 18 & 28 & \\
\hline $\mathrm{N}_{2}$ & 69 & 9 & 31 & 29 & & 26 & 6 & 20 & \\
\hline \multicolumn{10}{|l|}{ Metastasis } \\
\hline $\mathrm{M}_{0}$ & 368 & 63 & 154 & 151 & 0.782 & 134 & 44 & 90 & 0.228 \\
\hline$M_{1}$ & 11 & 1 & 5 & 5 & & 3 & 0 & 3 & \\
\hline \multicolumn{10}{|l|}{ Disease stage } \\
\hline 1 & 85 & 14 & 41 & 30 & 0.885 & 23 & 9 & 14 & 0.417 \\
\hline$\|$ & 114 & 19 & 47 & 48 & & 42 & 11 & 31 & \\
\hline III & 169 & 30 & 66 & 73 & & 69 & 24 & 45 & \\
\hline IV & 11 & 1 & 5 & 5 & & 3 & 0 & 3 & \\
\hline
\end{tabular}

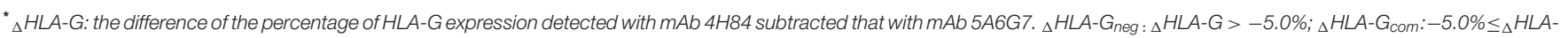
$\mathrm{G} \leq 5.0 \% ;{ }_{\Delta} H L A-G_{\text {pos }}:{ }_{\Delta} H L A-G>5.0 \%$.

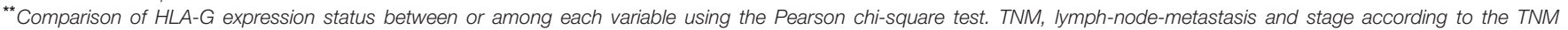
classification.

CI: 60.3-74.1) respectively, where patients with ${ }_{\Delta} \mathrm{HLA}-\mathrm{G}_{\text {neg }}$ had a better outcome than that of patients with ${ }_{\Delta} \mathrm{HLA}-\mathrm{G}_{\mathrm{com}}$ and ${ }_{\Delta}$ HLA-G $\mathrm{G}_{\text {pos }}$. Interestingly, when compared the survival between the patients with mAbs $4 \mathrm{H} 84^{\text {neg }} 5 \mathrm{~A} 6 \mathrm{G} 7^{\text {pos }}(n=40)$ and $\mathrm{mAbs}$ $4 \mathrm{H} 84{ }^{\text {pos }} 5 \mathrm{~A} 6 \mathrm{G} 7^{\text {neg }}(n=84)$, we found that patients with $\mathrm{mAbs}$ $4 \mathrm{H} 84^{\text {neg }} 5 \mathrm{~A} 6 \mathrm{G} 7^{\text {pos }}$ had a better survival than that of patients with $\mathrm{mAbs} 4 \mathrm{H} 84^{\text {pos }} 5 \mathrm{~A} 6 \mathrm{G} 7^{\text {neg }}(p=0.046$, Figure 2D). The mean survival for mAbs $4 \mathrm{H} 84^{\text {neg }} 5 \mathrm{~A} 6 \mathrm{G} 7^{\text {pos }}$ was 85.5 months $(95 \% \mathrm{CI}$ : $74.8-96.2)$, and mAbs $4 \mathrm{H} 84^{\text {pos }} 5 \mathrm{~A} 6 \mathrm{G} 7^{\text {neg }}$ was 68.1 months $(95 \%$ CI: 59.2-77.0), respectively.

To mitigate the heterogeneity of the samples on the prognistic value of ${ }_{\Delta} \mathrm{HLA}-\mathrm{G}$, we futher analyzed the relevance of ${ }_{\Delta} \mathrm{HLA}$ $G$ status to survival for patients with particular AJCC stages. The survival analysis was performed for patients with AJCC stage II and III, because limited evens were occurred in patietns with AJCC stage I $\left(\mathrm{N}_{\text {event }}=10\right)$ and stage IV $\left(\mathrm{N}_{\text {event }}=6\right)$. Data showed that, among patients with AJCC stage II, ${ }_{\Delta}$ HLA-G status was also obivously associated with the patient survival, the mean survival for ${ }_{\Delta} \mathrm{HLA}_{-} \mathrm{G}_{\text {neg }}(n=17){ }_{{ }_{\Delta}} \mathrm{HLA}-$ $\mathrm{G}_{\text {com }}(n=39)$, and ${ }_{\Delta} \mathrm{HLA}-\mathrm{G}_{\text {pos }}(n=42)$ was $99.3,79.1$, and 70.5 months, respectively $(p=0.031$ ). For the subgroups of stage II patients, significant difference for survival was also observed between the patients with ${ }_{\Delta} \mathrm{HLA}-\mathrm{G}_{\text {neg }}$ vs. ${ }_{\Delta} \mathrm{HLA}$ $\mathrm{G}_{\text {pos }}(p=0.012$; Figure $2 \mathrm{E})$. Among patients with AJCC stage III, though does not reach the statistical significance, the mean survival for ${ }_{\Delta}$ HLA-G $G_{\text {neg }}(n=27,72.7$ months) was much longer than patients with, ${ }_{,}$HLA-G $\mathrm{G}_{\text {com }}(n=62,53.6$ months $)$ and ${ }_{\Delta}$ HLA-G ${ }_{\text {pos }}(n=65,56.7$ months; $p=0.158$, Figure 2F).

\section{Value of ${ }_{\Delta} \mathrm{HLA}-\mathrm{G}$ Status on Prognosis for CRC Patients}

Finally, the prognostic value of the ${ }_{\Delta} \mathrm{HLA}-\mathrm{G}$ combined with CRC patient clinical parameters was analyzed (Table 4). By univariate analysis, primary tumor burden $\left(\mathrm{T}_{3+4}\right.$ vs. $\mathrm{T}_{1+2}, H R=2.504$, $p<0.001)$, regional lymph node $\left(\mathrm{N}_{1+2}\right.$ vs. $\mathrm{N}_{0}, H R=3.064$, $p<0.001)$, distant metastases $\left(\mathrm{M}_{1}\right.$ vs. $\mathrm{M}_{0}, H R=2.009$, $p=0.097$ ), and clinical disease stage (III + IV vs. I + II, $H R=3.142, p<0.001)$ was markedly associated with worse prognosis; However, ${ }_{\Delta} \mathrm{HLA}-\mathrm{G}$ neg $\left({ }_{\Delta} \mathrm{HLA}-\mathrm{G}\right.$ neg vs. ${ }_{\Delta} \mathrm{HLA}-\mathrm{G}$ com+pos, $H R=0.414, p=0.008)$ was obviously associated with a better prognosis. Furthermore, by multivariate analysis, data showed that primary tumor $(p=0.030)$ and ${ }_{\Delta}$ HLA-G status 
TABLE 3 | Log-rank Mantel-Cox analysis of clinical parameters in survival in CRC patients.

\begin{tabular}{|c|c|c|c|c|c|c|}
\hline Variables & & $\begin{array}{l}\text { No. } \\
\text { total }\end{array}$ & No. events & Mean survival & $95 \% \mathrm{Cl}$ & $\begin{array}{c}p- \\
\text { value }\end{array}$ \\
\hline \multirow[t]{2}{*}{ Sex } & Male & 192 & 65 & 72.0 & $66.2-77.7$ & 0.927 \\
\hline & Female & 147 & 48 & 73.4 & $66.6-80.1$ & \\
\hline \multirow[t]{2}{*}{ Age } & $\leq 66$ ys & 164 & 55 & 73.4 & $67.1-79.6$ & 0.755 \\
\hline & $>66$ ys & 175 & 58 & 71.6 & $65.4-77.8$ & \\
\hline \multirow[t]{3}{*}{ Tumor status } & $\mathrm{T}_{1+2}$ & 97 & 18 & 84.5 & $77.4-91.6$ & 0.001 \\
\hline & $\mathrm{T}_{3}$ & 228 & 87 & 67.6 & $62.1-73.1$ & \\
\hline & $\mathrm{T}_{4}$ & 14 & 8 & 60.6 & $40.1-81.2$ & \\
\hline \multirow[t]{3}{*}{ Nodal status } & $\mathrm{N}_{0}$ & 176 & 37 & 84.4 & 79.2-89.6 & $<0.001$ \\
\hline & $\mathrm{N}_{1}$ & 101 & 44 & 62.4 & $54.1-70.7$ & \\
\hline & $\mathrm{N}_{2}$ & 62 & 32 & 53.6 & $42.3-65.0$ & \\
\hline \multirow[t]{2}{*}{ Metastasis status } & $\mathrm{M}_{0}$ & 328 & 107 & 73.4 & $68.8-77.8$ & 0.089 \\
\hline & $M_{1}$ & 11 & 6 & 51.9 & $25.2-78.7$ & \\
\hline \multirow[t]{4}{*}{ Clinical stage } & 1 & 76 & 10 & 86.3 & 79.7-92.9 & $<0.001$ \\
\hline & $\|$ & 98 & 26 & 80.4 & $73.2-87.7$ & \\
\hline & III & 154 & 71 & 58.7 & $51.8-65.7$ & \\
\hline & IV & 11 & 6 & 51.9 & $25.1-78.7$ & \\
\hline \multirow[t]{2}{*}{ HLA-G (mAb 4H84) } & Neg & 98 & 29 & 76.7 & $69.0-84.5$ & 0.250 \\
\hline & Pos & 241 & 84 & 70.7 & $65.4-76.0$ & \\
\hline \multirow[t]{2}{*}{ HLA-G (mAb 5A6G7) } & Neg & 142 & 54 & 69.5 & $62.9-76.2$ & 0.268 \\
\hline & Pos & 197 & 59 & 74.9 & $69.0-80.8$ & \\
\hline \multicolumn{7}{|l|}{${ }_{\Delta} \mathrm{HLA}^{-G}$ status ${ }^{\star}$} \\
\hline & ${ }_{\Delta} \mathrm{HLA}-\mathrm{G}_{\text {neg }}$ & 57 & 10 & 87.9 & 79.4-96.4 & 0.017 \\
\hline & ${ }_{\Delta} \mathrm{HLA}-\mathrm{G}_{\mathrm{com}}$ & 143 & 48 & 71.0 & $64.0-77.9$ & \\
\hline & ${ }_{\Delta} \mathrm{HLA}-\mathrm{Gpos}$ & 139 & 55 & 67.2 & $60.3-74.1$ & \\
\hline $4 \mathrm{H} 84^{\text {neg }} 5$ A6G7 $7^{\text {pos }}$ & / & 40 & 8 & 85.5 & $74.8-96.2$ & 0.046 \\
\hline $4 \mathrm{H} 84^{\text {pos }} 5$ A6G $77^{\text {neg }}$ & / & 84 & 33 & 68.1 & $59.2-77.0$ & \\
\hline
\end{tabular}

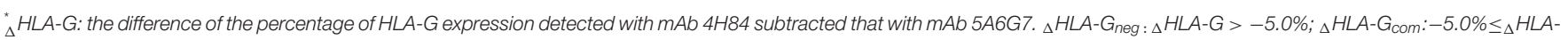
G $\leq 5.0 \% ;{ }_{\Delta} H L A-G_{\text {pos }}:{ }_{\Delta} H L A-G>5.0 \%$.

$(p=0.008)$ remain statistic significantly, indicating that ${ }_{\Delta} \mathrm{HLA}-$ $\mathrm{G}$ status could be an independent prognostic factor for CRC patients.

\section{DISCUSSION}

Since HLA-G was firstly found in cytotrophoblast in 1990 (16), immune regulation functions of HLA-G have been investigated extensively, and important roles of HLA-G in the maintenance for the fetal-maternal immunotolerance were established (17). However, with the HLA-G expression was observed in cancers for the first time in 1998, numerous studies have been carried out focusing on the basic biology and clinical significance of HLA$\mathrm{G}$ in malignancies $(2,18)$. In clinical settings and pre-clinical murine models, HLA-G expression was strongly related to the capability of tumor cell invasiveness and metastasis, to advanced disease stage and poor survival in cancer patients $(1,13)$. Thus far, the importance of HLA-G in cancer promotion and progression has been widely acknowledged. Consequently, HLA-G as cancer immunotherapy target was proposed.

One of the distinct features of $H L A-G$ is that, by gene alternative splicing, its primary transcript could generate at least seven isoforms (HLA-G1 HLA-G7) (9). However, it's reasonable more novel unrecognized HLA-G isoforms remains unveiled because different reading frame could be formed by the gene splicing. This is indeed in case of HLA-G as reported in a recent study (11). In that study, HLA-G expression in renal cancer lesions (RCC) was evaluated by immunohistochemistry (IHC) with different HLA-G antibodies including mAbs $4 \mathrm{H} 84$ and 5A6G7. Unexpectedly, in some RCC cases, IHC results showed that no immunostaining was detected with the mAb $4 \mathrm{H} 84$ but strongly with mAb 5A6G7 (mAbs $4 \mathrm{H} 84^{\text {neg }} 5 \mathrm{~A} 6 \mathrm{G} 7^{\mathrm{pos}}$ ). The staining pattern seems controversy to our prevailing knowledge that absence of mAb 4H84 labeling generally accounts for the lack of HLA-G expression. This is based on the fact that all previously identified seven HLA-G isoforms contains $\alpha 1$ domain and could be detected by the mAb $4 \mathrm{H} 84$.

In this context, we presented similar puzzled data of staining pattern (mAbs $4 \mathrm{H} 84^{\text {neg }} 5 \mathrm{~A} 6 \mathrm{G} 7^{\text {pos }}$ ) on the case-matched lung and ovarian cancers and lead to hot discussion by the participants during the 7th international conference on HLA-G (Paris, 2015. http://www.hlag2015.sitew.fr/\#Program.C). Noteworthy, now the unpredictable and unexpected immunostaining pattern could be explained by the findings revealed by Tronik-Le Roux et al. (11), that unrecognized HLA-G isoforms heretofore such as $\alpha 1$ domain-absent isoforms were presented in CRC samples. 

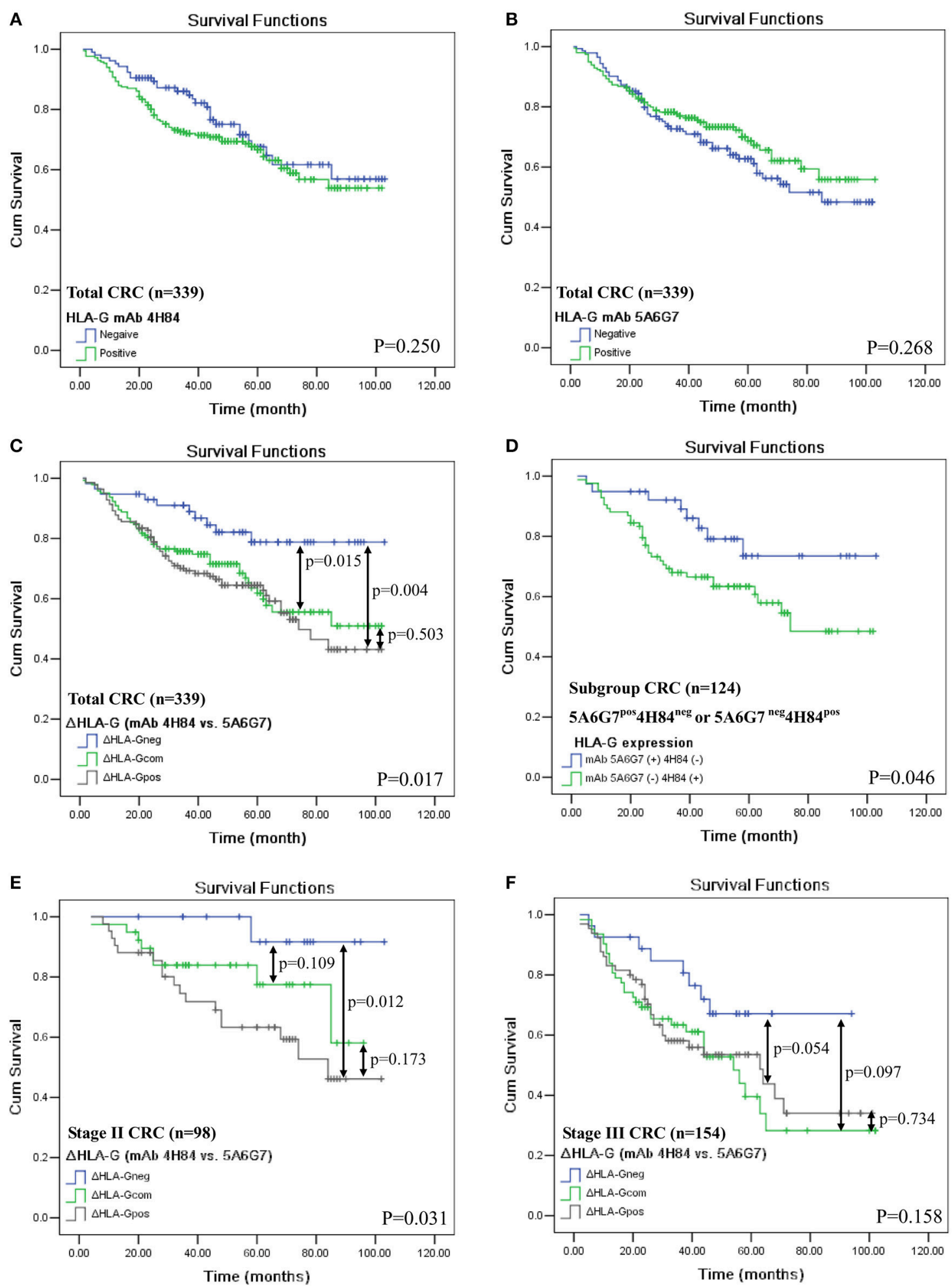

FIGURE 2 | Kaplan-Meier survival analysis of HLA-G expression status with mAbs 4H84 or 5A6G7 in CRC patients. (A) Comparison between HLA-Gneg and HLA-Gpos with mAb 4H84 in the whole cohort of CRC patients $(p=0.250)$; (B) between HLA-Gneg and HLA-Gpos with mAb 5A6G7 in the whole cohort of CRC patients $(p=0.268)$; (C) among patient with ${ }_{\Delta} \mathrm{HLA}-\mathrm{G}_{\text {neg, }}{ }_{\Delta} \mathrm{HLA}-\mathrm{G}_{\text {com }}$ and ${ }_{\Delta} \mathrm{HLA}-\mathrm{G}_{\text {pos }}(p=0.017)$ in the whole cohort of CRC patients. (D) between patients with

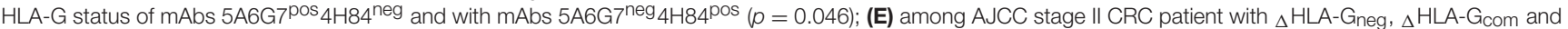
${ }_{\Delta}$ HLA-Gpos $(p=0.031)$; and $(\mathbf{F})$ among AJCC stage III CRC patient with ${ }_{\Delta}$ HLA-Gneg, ${ }_{\Delta}$ HLA-G com $_{\text {and }}{ }_{\Delta}$ HLA-Gpos $(p=0.158)$. Note: $p$-value in double-head arrow represents the comparison between subgroups of the CRC patients indicated. 
TABLE 4 | Cox proportional hazards model analysis of multi-variables in survival for CRC patients.

\begin{tabular}{|c|c|c|c|c|c|}
\hline \multirow[t]{2}{*}{ Variables } & \multirow[t]{2}{*}{ Categories } & \multicolumn{2}{|c|}{ Univariate analysis } & \multicolumn{2}{|c|}{ Multivariate analysis } \\
\hline & & HR (95\% Cl) & $P$ & HR (95\% Cl) & $P$ \\
\hline Sex & Male vs. Female & $0.983(0.667-1.427)$ & 0.927 & & \\
\hline Age (years) & $>66$ vs. $\leq 66$ & $1.060(0.733-1.534)$ & 0.756 & & \\
\hline Tumor status & $\mathrm{T}_{3+4}$ vs. $\mathrm{T}_{1+2}$ & $2.504(1.512-4.147)$ & $<0.001$ & 1.793 (1.059-3.035) & 0.030 \\
\hline Nodal status & $\mathrm{N}_{1+2}$ vs. $\mathrm{N}_{0}$ & $3.064(2.062-4.554)$ & $<0.001$ & $0.919(0.107-7.921)$ & 0.919 \\
\hline Metastasis status & $M_{1}$ vs. $M_{0}$ & $2.009(0.881-4.580)$ & 0.097 & 1.047 (0.419-2.612) & 0.922 \\
\hline Clinical stage & III+IV vs. I+II & $3.142(2.108-4.683)$ & $<0.001$ & $2.913(0.322-26.34)$ & 0.341 \\
\hline HLA-G (mAb 4H84) & Pos vs. Neg & 1.267 (0.830-1.933) & 0.272 & & \\
\hline HLA-G (mAb 5A6G7) & Pos vs. Neg & $0.812(0.561-1.175)$ & 0.270 & & \\
\hline${ }_{\Delta}$ HLA-G status ${ }^{\star}$ & $\begin{array}{l}{ }_{\Delta} \mathrm{HLA}-\mathrm{G}_{\text {neg }} \text { vs. } \\
{ }_{\Delta} \mathrm{HLA}-\mathrm{G}_{\mathrm{com}+\mathrm{pos}}\end{array}$ & $0.414(0.216-0.792)$ & 0.008 & $0.416(0.217-0.798)$ & 0.008 \\
\hline
\end{tabular}

$H R$, hazard ratio; $95 \% \mathrm{Cl}=95 \%$ confidence interval.

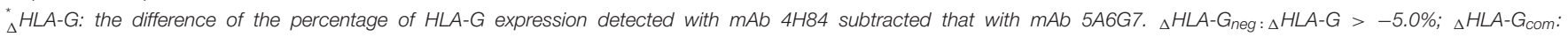
$-5.0 \% \leq{ }_{\Delta} H L A-G \leq 5.0 \% ;{ }_{\Delta} H L A-G_{p o s}:{ }_{\Delta} H L A-G>5.0 \%$.

The very instructive findings raises the questions whether these novel HLA-G proteins are of clinical significance because similar, distinct or opposing functions was observed among different isoforms.

Substantial previous evidence has proved that HLA-G is a crucial tumor-driven immune escape factor involved in alterating the anti-tumor responses of immune contexture of solid tumors like CRC, and thus in determination of the fate of tumor development and patient clinical outcome (1). Through binding to the immune inhibitory receptors (particularly ILT2 and/or ILT4) expressed on various immune cells, HLA-G could directly or indirectly impair anti-tumor immune responses (2). Accumulating data revealed that HLA-G has comprehensive immune suppressive functions to T cells, B cells, NK cells and DCs, and to enhance the generation of immune regulatory cells such as MDSCs, DC-10 and M2-macrophages (19-23). Among HLA-G isofroms, the immune suppression mediated by HLA-G1 and HLA-G5 isoforms was well documented by different research groups, including ours. We found that HLAG1 expressed in ovarian cancer cell lines NIH:OVCAR-3 and HO-8910 $(6,24)$, hepatocellular carcinoma cell line Hep G2 (25), lung adenocarcinoma cell line A549 (26) could dramatically decrease the NK cell cytolysis. We also found that by blocking the HLA-G with $\mathrm{mAb} 87 \mathrm{G}$ or its receptor ILT2 expressed on the effector NK-92 cell line could significantly reverse the NK cell lysis function $(24,26)$. Furthermore, HLA-G1 and HLAG5 isoforms in NK cell cytolysis suppression is dependent on the level of both HLA-G1 and HLA-G5 expression. Compared to HLA-G1, HLA-G5 has a more potent inhibition effect on the NK cytolysis. Moreover, HLA-G1 and HLA-G5 isoforms have an additive effect on NK cytolysis suppression $(27,28)$. HLA-G1/ILT2 engagement on T cells could result in inhibition of CD4+ T cell alloproliferation and CD8+ and V $\gamma 9 \mathrm{~V} \delta 2 \mathrm{~T}$ cell cytolysis and IFN- $\gamma$ production (29-31). HLA-G5/ILT2 mediated signal was observed to supress B cell immunoglobulin production, and HLA-G5/ILT4 interaction impair phagocytosis and reactive oxygen species production of neutrophils $(32,33)$. Other functions such as impairment of the expression and function of chemokine receptors in T cells, NK cells and B cells mediated by HLA-G5/ILT2 signaling pathway was also reported (34).

As expected that, like other HLA antigens, subtle structural alterations in HLA-G molecules can have dramatic effects on innate and adaptive immune modulation, and consequently, related to different clinical significance $(35,36)$. In this scenario, recent studies revealed that the nature of the bound peptide could influence the substructure and stability of HLA-G, and a single amino acid exchange in the $\alpha 2$ domain in allelic HLAG subtypes of $H L A-G^{*} 01: 01$ and $H L A-G^{*} 01: 04$ has obivously different capability in NK cell lysis inhibition (36, 37). HLAG3 was found less efficient than HLA-G1 at inducing HLAE surface expression (38). Moreover, unlike HLA-G1, HLAG3 could not inhibit human monocyte/macrophage-mediated swine endothelial cell lysis or NK cells against K562 cells (39, 40). These findings indicated that distinct structure of HLA-G molecules or isoforms features with unique biological functions and could impact on its recognition by receptors of both innate and adaptive immune systems.

To evaluate whether different structural HLA-G molecaules have different clinical relavence, in this study, HLA-G expression in 379 case-matched primary CRC lesions were analyzed by IHC with mAb $4 \mathrm{H} 84$ and mAb 5A6G7. Different percentage of HLA-G expression was commonly observed between the case-matched serial sections when using the mAb $4 \mathrm{H} 84$ and $\mathrm{mAb}$ 5A6G7. Furthermore, clinical relevance of the difference of HLA-G expression ( ${ }_{\Delta}$ HLA-G) between mAbs 4H84 and 5A6G7 was evaluated. Our data revealed that lower percentage of HLA-G expression detected with $\mathrm{mAb}$ $4 \mathrm{H} 84$ than mAb 5A6G7 ( ${ }_{\Delta} \mathrm{HLA}-\mathrm{G}_{\mathrm{neg}}$ ) was found in $16.9 \%$ (64/379), comparable percentage detected with both antibodies $\left({ }_{\Delta} \mathrm{HLA}-\mathrm{G}_{\mathrm{com}}\right)$ was found in $42.0 \%$ (159/379), higher percentage of HLA-G expression detected with $\mathrm{mAb} 4 \mathrm{H} 84$ than $\mathrm{mAb}$ 5A6G7 $\left({ }_{\Delta}\right.$ HLA-G pos $\left._{\text {pos }}\right)$ was found in $41.2 \%(156 / 379)$ of CRC samples, respectively. Patients with ${ }_{\Delta} \mathrm{HLA}-\mathrm{G}_{\text {neg }}$ had significantly better survival than those with ${ }_{\Delta} \mathrm{HLA}_{-} \mathrm{G}_{\mathrm{com}}$ and ${ }_{\Delta} \mathrm{HLA}-$ $\mathrm{G}_{\text {pos }}$ CRC patients $(p=0.017)$. A better predictive value 
of ${ }_{\Delta}$ HLA-G $G_{\text {neg }}$ was also observed for patients with either AJCC stage II or III. Moreover, patients with staining pattern $4 \mathrm{H} 84^{\text {neg }} 5 \mathrm{~A} 6 \mathrm{G} 7^{\text {pos }}$ had a better survival than that of patients with $4 \mathrm{H} 84^{\mathrm{pos}} 5 \mathrm{~A} 6 \mathrm{G} 7^{\text {neg }}(p=0.046)$. Multivariate analysis by Cox proportional hazards model also showed that ${ }_{\Delta} \mathrm{HLA}-\mathrm{G}$ could be an independent prognostic factor for CRC patients $(p=0.008)$.

Different clinical significance of HLA-G expression in cancers detected with mAb $4 \mathrm{H} 84$ and mAb 5A6G7 was also reported in previous studies. HLA-G expression detected with mAb $4 \mathrm{H} 84$ was found strongly relative to clinical stage and poor prognosis in lung cancers, while no such significance was observed for HLA-G5/-G6 detected with mAb 5A6G7 (26, 41). Unlike detected with mAb 4H84, HLA-G expression detected with $\mathrm{mAb} 5 \mathrm{~A} 6 \mathrm{G} 7$ was also found to unrelated to clinical parameters such as FIGO stage and prognosis in ovarian cancers $(14,42)$. Thus, the immunostaining pattern for HLA-G expression with $4 \mathrm{H} 84^{\text {neg }} 5 \mathrm{~A} 6 \mathrm{G} 7^{\text {pos }}$ strengthen the existence of novel $\alpha 1$ domainabsent HLA-G isoforms which could not be probed by the $\mathrm{mAb} 4 \mathrm{H} 84$. However, their specific function in physiological and pathological conditions still remains to be determined. To this end, being lack of currently available commercial antibodies for those novel HLA-G isoforms, a large campaign to develop new antibodies is extremely necessary and even inevitable.

\section{REFERENCES}

1. Lin A, Yan WH. HLA-G expression in cancers: roles in immune evasion, metastasis and target for therapy. Mol Med. (2015) 21:782-91. doi: 10.2119/molmed.2015.00083

2. Carosella ED, Rouas-Freiss N, Tronik-Le Roux D, Moreau P, LeMaoult J. HLA-G: an immune checkpoint molecule. Adv Immunol. (2015) 127:33-144. doi: 10.1016/bs.ai.2015.04.001

3. Agaugue S, Carosella ED, Rouas-Freiss N. Role of HLA-G in tumor escape through expansion of myeloid-derived suppressor cells and cytokinic balance in favor of Th2 versus Th1/Th17. Blood (2011) 117:7021-31. doi: 10.1182/blood-2010-07-294389

4. Zhang W, Liang S, Wu J, Horuzsko A. Human inhibitory receptor immunoglobulin-like transcript 2 amplifies CD11b+Gr1+ myeloid-derived suppressor cells that promote long-term survival of allografts. Transplantation (2008) 86:1125-34. doi: 10.1097/TP.0b013e318186fccd

5. Lin A, Zhang X, Xu HH, Xu DP, Ruan YY, Yan WH. HLA-G expression is associated with metastasis and poor survival in the Balb/c nu/nu murine tumor model with ovarian cancer. Int J Cancer (2012) 131:150-7. doi: 10.1002/ijc.26375

6. Lin A, Xu HH, Xu DP, Zhang X, Wang Q, Yan WH. Multiple steps of HLA-G in ovarian carcinoma metastasis: alter NK cytotoxicity and induce matrix metalloproteinase-15 (MMP-15) expression. Hum Immunol. (2013) 74:439-46. doi: 10.1016/j.humimm.2012.11.021

7. Liu H, Liu X, Jin H, Yang F, Gu W, Li X. Proteomic analysis of knock-down HLA-G in invasion of human trophoblast cell line JEG-3. Int J Clin Exp Pathol. (2013) 6:2451-9.

8. Guo Y, Lee CL, So KH, Gao J, Yeung WS, Yao Y, et al. Soluble human leukocyte antigen-g5 activates extracellular signal-regulated protein kinase signaling and stimulates trophoblast invasion. PLOS ONE (2013) 8:e76023. doi: 10.1371/journal.pone.0076023

9. Paul P, Cabestre FA, Ibrahim EC, Lefebvre S, Khalil-Daher I, Vazeux $\mathrm{G}$, et al. Identification of HLA-G7 as a new splice variant of the HLA-G mRNA and expression of soluble HLA-G5, -G6, and -G7
Summary, our preliminary findings revealed that novel unidentified HLA-G isoforms recognized by mAbs 5A6G7 but not $4 \mathrm{H} 84$ might be existed in colorectal cancers. Moreover, HLA$\mathrm{G}$ isoforms recognized by $\mathrm{mAb} 5 \mathrm{~A} 6 \mathrm{G} 7$ is of different clinical significant from that of the isoforms recognized by mAb $4 \mathrm{H} 84$. In the era of the precision medicine, the inter- and intra-tumor heterogeneity caused by complexity of the validated and even novel HLA-G isoforms, interpretation of the significance of HLA$G$ in cancers must be with extreme caution before their distinct roles are elucidated.

\section{AUTHOR CONTRIBUTIONS}

AL and W-HY: study design; XZ and AL: performed experiments; R-LZ, J-GZ, and W-JZ: material support and data acquisition; $\mathrm{AL}$ and W-HY: performed statistical analysis and drafted the manuscript. All authors read and approved the final manuscript.

\section{FUNDING}

This work was supported by grants from National Natural Science Foundation of China (31370920, 81372247), Science and Technology Bureau of Zhejiang Province (2013C33112) and by Zhejiang Provincial program for the cultivation of high-level innovative health talents.

transcripts in human transfected cells. Hum Immunol. (2000) 61:1138-49. doi: 10.1016/S0198-8859(00)00197-X

10. Yan WH, Fan LA. Residues Met76 and Gln79 in HLA-G alpha1 domain involve in KIR2DL4 recognition. Cell Res. (2005) 15:176-82. doi: $10.1038 /$ sj.cr.7290283

11. Tronik-Le Roux D, Renard J, Verine J, Renault V, Tubacher E, LeMaoult J, et al. Novel landscape of HLA-G isoforms expressed in clear cell renal cell carcinoma patients. Mol Oncol. (2017) 11:1561-78. doi: 10.1002/1878-0261.12119

12. Edge SB, Compton CC. The American Joint Committee on Cancer: the 7th edition of the AJCC cancer staging manual and the future of TNM. Ann Surg Oncol. (2010) 17:1471-4. doi: 10.1245/s10434-010-0985-4

13. Zhang RL, Zhang X, Dong SS, Hu B, Han QY, Zhang JG, et al. Predictive value of different proportion of lesion HLA-G expression in colorectal cancer. Oncotarget (2017) 8:107441-51. doi: 10.18632/oncotarget.22487

14. Zhang X, Han QY, Li JB, Ruan YY, Yan WH, Lin A. Lesion HLA-G5/-G6 isoforms expression in patients with ovarian cancer. Hum Immunol. (2016) 77:780-4. doi: 10.1016/j.humimm.2015.12.003

15. Chew SF, Kanaan C, Tait BD. HLA expression and cancer-14th IHIWS immunohistochemistry quality control exercise exchange results. Tissue Antigens (2007) 69(Suppl. 1):248-51. doi: 10.1111/j.1399-0039.2006.774_2.x

16. Kovats S, Main EK, Librach C, Stubblebine M, Fisher SJ, DeMars R. A class I antigen, HLA-G, expressed in human trophoblasts. Science (1990) 248:220-3. doi: 10.1126/science. 2326636

17. Carosella ED, Moreau P, Le Maoult J, Le Discorde M, Dausset J, Rouas-Freiss N. HLA-G molecules: from maternal-fetal tolerance to tissue acceptance. $A d v$ Immunol. (2003) 81:199-252. doi: 10.1016/S0065-2776(03)81006-4

18. Paul P, Rouas-Freiss N, Khalil-Daher I, Moreau P, Riteau B, Le Gal FA, et al. HLA-G expression in melanoma: a way for tumor cells to escape from immunosurveillance. Proc Natl Acad Sci USA. (1998) 95:4510-5. doi: $10.1073 /$ pnas.95.8.4510

19. Bainbridge DR, Ellis SA, Sargent IL. HLA-G suppresses proliferation of $\mathrm{CD}^{+}$T-lymphocytes. J Reprod Immunol. (2000) 48:17-26. doi: 10.1016/S0165-0378(00)00070-X 
20. Baudhuin J, Lesport E, Sousa S, Migraine J, Vigneron J, Lemaoult J, et al. HLA-G inhibition of NK-cell cytolytic function is uncoupled from tumor cell lipid raft reorganization. Eur J Immunol. (2012) 42:700-9. doi: 10.1002/eji.201141930

21. Kostlin N, Ostermeir AL, Spring B, Schwarz J, Marme A, Walter CB, et al. HLA-G promotes myeloid-derived suppressor cell accumulation and suppressive activity during human pregnancy through engagement of the receptor ILT4. Eur J Immunol. (2017) 47:374-84. doi: 10.1002/eji.201646564

22. Amodio G, Comi M, Tomasoni D, Gianolini ME, Rizzo R, LeMaoult J, et al. HLA-G expression levels influence the tolerogenic activity of human DC-10. Haematologica (2015) 100:548-57. doi: 10.3324/haematol.2014.113803

23. Nunez SY, Ziblat A, Secchiari F, Torres NI, Sierra JM, Raffo Iraolagoitia XL, et al. Human M2 macrophages limit NK cell effector functions through secretion of TGF-beta and engagement of CD85j. J Immunol. (2018) 200:1008-15. doi: 10.4049/jimmunol.1700737

24. Lin A, Yan WH, Xu HH, Gan MF, Cai JF, Zhu M, et al. HLA-G expression in human ovarian carcinoma counteracts NK cell function. Ann Oncol. (2007) 18:1804-9. doi: 10.1093/annonc/mdm356

25. Lin A, Chen HX, Zhu CC, Zhang X, Xu HH, Zhang JG, et al. Aberrant human leucocyte antigen-G expression and its clinical relevance in hepatocellular carcinoma. J Cell Mol Med. 14:2162-71. doi: 10.1111/j.1582-4934.2009.00917.x

26. Lin A, Zhu CC, Chen HX, Chen BF, Zhang X, Zhang JG, et al. Clinical relevance and functional implications for human leucocyte antigeng expression in non-small-cell lung cancer. J Cell Mol Med. 14:2318-29. doi: 10.1111/j.1582-4934.2009.00858.x

27. Zhang WQ, Xu DP, Liu D, Li YY, Ruan YY, Lin A, et al. HLA-G1 and HLAG5 isoforms have an additive effect on NK cytolysis. Hum Immunol. (2014) 75:182-9. doi: 10.1016/j.humimm.2013.11.001

28. Chen BG, Xu DP, Lin A, Yan WH. NK cytolysis is dependent on the proportion of HLA-G expression. Hum Immunol. (2013) 74:286-9. doi: 10.1016/j.humimm.2012.12.005

29. Lesport E, Baudhuin J, Sousa S, LeMaoult J, Zamborlini A, Rouas-Freiss N, et al. Inhibition of human gamma delta [corrected] T-cell antitumoral activity through HLA-G: implications for immunotherapy of cancer. Cell Mol Life Sci. (2011) 68:3385-99. doi: 10.1007/s00018-011-0632-7

30. Le Gal FA, Riteau B, Sedlik C, Khalil-Daher I, Menier C, Dausset J, et al. HLA-G-mediated inhibition of antigen-specific cytotoxic T lymphocytes. Int Immunol. (1999) 11:1351-6. doi: 10.1093/intimm/11.8.1351

31. LeMaoult J, Krawice-Radanne I, Dausset J, Carosella ED. HLA-G1-expressing antigen-presenting cells induce immunosuppressive CD4+ T cells. Proc Natl Acad Sci USA. (2004) 101:7064-9. doi: 10.1073/pnas.0401922101

32. Baudhuin J, Migraine J, Faivre V, Loumagne L, Lukaszewicz AC, Payen D, et al. Exocytosis acts as a modulator of the ILT4-mediated inhibition of neutrophil functions. Proc Natl Acad Sci USA. (2013) 110:17957-62. doi: 10.1073/pnas.12215 35110
33. Naji A, Menier C, Morandi F, Agaugue S, Maki G, Ferretti E, et al. Binding of HLA-G to ITIM-bearing Ig-like transcript 2 receptor suppresses B cell responses. J Immunol. (2014) 192:1536-46. doi: 10.4049/jimmunol.1300438

34. Morandi F, Rouas-Freiss N, Pistoia V. The emerging role of soluble HLA-G in the control of chemotaxis. Cytokine Growth Factor Rev. (2014) 25:327-35. doi: 10.1016/j.cytogfr.2014.04.004

35. Aptsiauri N, Ruiz-Cabello F, Garrido F. The transition from HLA-I positive to HLA-I negative primary tumors: the road to escape from T-cell responses. Curr Opin Immunol. (2018) 51:123-32. doi: 10.1016/j.coi.2018.03.006

36. Walpole NG, Kjer-Nielsen L, Kostenko L, McCluskey J, Brooks AG, Rossjohn $\mathrm{J}$, et al. The structure and stability of the monomorphic HLA-G are influenced by the nature of the bound peptide. J Mol Biol. (2010) 397:467-80. doi: 10.1016/j.jmb.2010.01.052

37. Celik AA, Simper GS, Huyton T, Blasczyk R, Bade-Doding C. HLA$\mathrm{G}$ mediated immune regulation is impaired by a single amino acid exchange in the alpha 2 domain. Hum Immunol. (2018) 79:453-62. doi: 10.1016/j.humimm.2018.03.010

38. Teklemariam T, Zhao L, Hantash BM. Full-length HLA-G1 and truncated HLA-G3 differentially increase HLA-E surface localization. Hum Immunol. (2012) 73:898-905. doi: 10.1016/j.humimm.2012.06.007

39. Eguchi H, Maeda A, Lo PC, Matsuura R, Esquivel EL, Asada M, et al. HLA-G1, but not HLA-G3, Suppresses human Monocyte/Macrophagemediated swine endothelial cell Lysis. Transpl Proc. (2016) 48:1285-7. doi: 10.1016/j.transproceed.2015.10.070

40. Zhao L, Teklemariam T, Hantash BM. Mutated HLA-G3 localizes to the cell surface but does not inhibit cytotoxicity of natural killer cells. Cell Immunol. (2014) 287:23-6. doi: 10.1016/j.cellimm.2013.11.005

41. Yan WH, Liu D, Lu HY, Li YY, Zhang X, Lin A. Significance of tumour cell HLA-G5/-G6 isoform expression in discrimination for adenocarcinoma from squamous cell carcinoma in lung cancer patients. J Cell Mol Med. (2015) 19:778-85. doi: 10.1111/jcmm.12400

42. Jung YW, Kim YT, Kim SW, Kim S, Kim JH, Cho $\mathrm{NH}$, et al. Correlation of human leukocyte antigen-G (HLA-G) expression and disease progression in epithelial ovarian cancer. Reprod Sci. (2009) 16:1103-11. doi: $10.1177 / 1933719109342131$

Conflict of Interest Statement: The authors declare that the research was conducted in the absence of any commercial or financial relationships that could be construed as a potential conflict of interest.

Copyright (c) 2018 Lin, Zhang, Zhang, Zhang, Zhou and Yan. This is an open-access article distributed under the terms of the Creative Commons Attribution License (CC $B Y)$. The use, distribution or reproduction in other forums is permitted, provided the original author(s) and the copyright owner(s) are credited and that the original publication in this journal is cited, in accordance with accepted academic practice. No use, distribution or reproduction is permitted which does not comply with these terms. 